\title{
Fashion victim
}

It's all sewn up.

\section{Stephen Gaskell}

Robert-Jay Wharmby wanted to take over the world. Not in an evil-mastermind way, though. No, Rob wanted to take over the world of cutting-edge fashion. From Milan to Cape Town, Rob wanted the name Wharmby to be whispered in the same reverential tones as Prada and Burberry. Killer designs, not guns, would be his instruments of control.

Rob got off to a shaky start.

The lucent material he chose for his fashion house's summer collection disintegrated in the heat, leaving several models groping for their dignity. A pair of his Make 'Em Sweat sports vests short-circuited, forcing a 12-year-old boy to more than perspire. A line of business jackets with embedded newsfeeds got hacked by an anarchist group, nearly causing a stock-market meltdown when some city traders read about a fictitious collapse and panic sold.

Rob got farmed out to the Tokyo studio and told to buck up his ideas.

Life in Japan wasn't easy.

For starters, he was big by Western standards and found everything from his keyboard to his futon, to be, if not unfeasibly small, then at least irritatingly so. At the studio he found that the other designers had little time for him, busy with their own creations during the day and their families at night. When it came to his own work he found himself hesitant, overly conscious of making more mistakes.

He was afraid ideas that might've been brilliant back home - the Ultra Bra that made breasts bigger through thermal stimulation, the Always-Clean Shirt that went plastic-like at the touch of any liquid (from rain or spilt drinks to injudicious vomiting) thus making sodden clothes a problem of the past, and the Inflatable Collar that allowed drunks to pass-out in comfort - would bomb in this culture of deference and proper conduct.

One night he found himself eating alone at a modern sushi bar. The restaurant was located in a vast underground shopping precinct at the intersection of several of Tokyo's transport lines. It must've been frequented by all manner of people, but Rob found it impossible to determine anything about the lone diners beyond their age and sex. The food was superb moist ginger, spicy wasabi, melt-on-thetongue tuna - but he couldn't enjoy it.

All he wanted to do was talk to someone.

Later, disheartened, he found himself wandering into a pachinko parlour - a gambling house packed with row upon row of noisy, colourful slot machines. Men and women sat on high stools, feeding a constant stream of yen into the voracious games, their faces long, their backs bent. Rob played a couple of times, but found himself getting more depressed and left.

Outside, he watched several drunk businessmen stumble into a capsule hotel. The places offered cheap, coffin-like rooms for workers who couldn't - or didn't want to - go home. Most of them had comics in the basement where guests could lounge in their crisp, hotel-provided pyjamas and read manga. The only thing they didn't provide were clean clothes for the next day.

That night Rob slept a restless, dreamsuffused sleep - and woke up inspired.

At work he told his boss he wanted to put on a small show.

"Most excellent idea of outstanding promise," said his boss in the unusual grammatical way Rob had got used to when using his As-You-Speak interpreter. Buoyant, Rob attacked his designs with gusto, working late into the night for many days.

A few weeks later, Rob found himself issuing instructions to the models who would be wearing his new designs. Pausing from the preparations, he peered out from the backstage area onto a sea of expectant faces.

There was Heidi Bass, the chief buyer from Slum. There was Eloise Calandre, Vogue London's Far East correspondent.

It was make or break time for the Wharmby label.

For the first act the middle of the catwalk was transformed into a makeshift sushi bar counter. Models strutted down the sides and sat themselves at one of the dozen stools arrayed around the counter.

Over the electro-surge music, a voice narrated proceedings.

"Why lonely, Japanese person?" The audience shifted uncomfortably. "With Wharmby technology you can find the perfect dining partner." At those words several of the models changed seats and began animated conversations with their new neighbours. "Clothes have special microchip with personal data. Let you know when pass like-minded individual."

An ocean of silence greeted the words.

Rob thought his Smart Moves shirts and blouses would fare better. The catwalk became an aisle in a pachinko parlour and the models zombie-like gamblers. Beyond, a big screen showed a graphic of vital function monitors sewn into the shirts' collars.

"When you need it most, Wharmby technology rouse your mind!"

The graphic zoomed in. As microneedles pumped stimulants into the simulated veins, the real-life models perked up. The glitter and churn of jackpot wins followed.

The audience stayed quiet.

As the final act began, Rob noticed his boss heading in his direction, face livid.

He whispered fiercely: "You shame Japanese by bringing into spotlight culture of loneliness and addiction."

Don't forget overworking, Rob thought glumly, glancing at the catwalk.

His jaw dropped.

One minute the male model was clothed in a smart business suit, the next he was naked. The chameleon fabric meant to fake a change of clothes had malfunctioned. Rob felt like committing hara-kiri.

And then there came a clap. Followed by another. And another.

Someone else joined in. And somebody else.

Soon the whole room was on its feet in wild applause.

The noise was deafening.

Rob felt somebody grasp his shoulder. "I understand Wharmby philosophy now!" his boss shouted, grinning. "Make Japanese confront true nature. Very clever!"

Rob smiled.

Perhaps he would take over the world. Stephen Gaskell has sold fiction to many venues including Interzone and COSMOS. Usually years behind what's in fashion, this is his attempt at getting ahead. He blogs at www.stephengaskell.com. Join the discussion of Futures in Nature at go.nature.com/QMAm2a 